\title{
Doença celíaca e constipação: uma manifestação clínica atípica e pouco frequente
}

\author{
Celiac disease and constipation: an uncommon atypical clinical manifestation
}

\author{
Cristiane Boé ${ }^{1}$, Adriana Chebar Lozinsky ${ }^{1}$, Francy Reis Patrício ${ }^{2}$, Jacy Alves B. de Andrade ${ }^{3}$, Ulysses Fagundes-Neto ${ }^{4}$
}

\section{RESUMO}

Objetivo: Relatar dois casos de doença celíaca (DC) com manifestação de constipação.

Descrição do caso: Dois pacientes do sexo feminino, com 18 e 30 meses de idade, respectivamente, apresentando história de constipação crônica refratária ao tratamento. Como apresentavam concomitantemente baixo ganho ponderal e estatural, foi realizada investigação da função digestiva-absortiva, que resultou positiva para o anticorpo IgA antitransglutaminase tecidual. O diagnóstico de DC foi confirmado por biópsia de intestino delgado que revelou atrofia vilositária moderada/intensa e infiltrado linfocítico intraepitelial. Um mês após o início do tratamento com dieta isenta de glúten, ambas as pacientes passaram a apresentar fezes pastosas diariamente.

Comentários: A DC pode se apresentar nas formas clássica, assintomática e atípica, em que manifestações isoladas como constipação podem retardar o diagnóstico.

Palavras-chave: constipação intestinal; doença celíaca; criança.

\section{ABSTRACT}

Objective: To report two cases of patients with celiac disease (CD) whose main complaint was chronic constipation.

Case description: Two girls, aged 18 and 30 months, had chronic constipation refractory to standard treatment.

Instituição: Disciplina de Gastroenterologia do Departamento de Pediatria da Escola Paulista de Medicina da Universidade Federal de São Paulo (Unifesp), São Paulo, SP, Brasil

${ }^{1}$ Residente da Disciplina de Gastroenterologia do Departamento de Pediatria da Escola Paulista de Medicina da Unifesp, São Paulo, SP, Brasil

2Doutora em Anatomia Patológica pela Escola Paulista de Medicina da Unifesp; Professora Associada do Departamento de Anatomia Patológica da Escola Paulista de Medicina da Unifesp, São Paulo, SP, Brasil

${ }^{3}$ Doutora em Gastroenterologia pelo Departamento de Pediatria da Escola Paulista de Medicina da Unifesp, São Paulo, SP, Brasil

${ }^{4}$ Doutor em Gastroenterologia e Pediatria pela Escola Paulista de Medicina da Unifesp; Professor Titular da Disciplina de Gastroenterologia do Departamento de Pediatria da Escola Paulista de Medicina da Unifesp, São Paulo, SP, Brasil
Both patients concomitantly evidenced low weight gain and short stature. The investigation of the digestive-absorptive function was positive for $\operatorname{Ig} A$ antibodies against tissue transglutaminase. The diagnosis of $\mathrm{CD}$ was confirmed by a small bowel biopsy that showed moderate/severe villous atrophy and increased intraepithelial lymphocytic infiltration. One month after starting the dietary treatment with a glutenfree diet, both patients recovered from constipation, with the passage of soft stools daily.

Comments: CD may be presented in the classical, asymptomatic or atypical forms. In the latter form, isolated manifestations, surch as constipation, delay the diagnosis of the disease.

Key-words: constipation; celiac disease; child.

\section{Introdução}

A doença celíaca (DC) é uma intolerância permanente ao glúten, caracterizada por atrofia total ou subtotal da mucosa do intestino delgado proximal, hiperplasia das criptas e infiltrado linfocítico intraepitelial, com consequente má absorção dos nutrientes da dieta em indivíduos geneticamente suscetíveis ${ }^{(1)}$. A DC é considerada uma enteropatia crônica imunomediada ${ }^{(2)} \mathrm{e}$ apresenta íntima associação com o antígeno de histocompatibilidade (HLA) da classe II, DQ2 e DQ8 ${ }^{(3)}$.

A forma clássica da DC, descrita em 1888 por Samuel Gee, apud Sdepanian, Morais e Fagundes-Neto ${ }^{(3)}$,

\author{
Endereço para correspondência: \\ Cristiane Boé \\ Rua Mavari, 111 - Mooca \\ CEP 03181-110 - São Paulo/SP \\ E-mail: cristianeboe@hotmail.com \\ Fonte financiadora: Bolsa Produtividade em Pesquisa - Conselho Nacio- \\ nal de Desenvolvimento Científico e Tecnológico (CNPq), Processo $n^{\circ}$ \\ 304.150/2009-6 \\ Conflito de interesse: nada a declarar
}

Recebido em: 27/5/2011

Aprovado em: 18/10/2011 
caracteriza-se por diarreia crônica, distensão abdominal, perda de peso e/ou retardo no ritmo do crescimento, vômitos, dor abdominal, irritabilidade e atrofia da musculatura glútea $^{(4)}$. Embora essa ainda seja a forma mais frequente de manifestação clínica da DC, as formas atípica e assintomática vêm sendo mais relatadas.

Por um lado, a descrição de constipação como manifestação atípica da DC é pouco frequente na literatura, principalmente em Pediatria. Egan-Mitchell e McNicholl ${ }^{(5)}$, em 1972, realizaram uma análise de 112 crianças com diagnóstico de DC e encontraram $12(10,7 \%)$ com constipação. Por outro, Sharma, Poddar e Yachha ${ }^{(6)}$, em 2007, realizaram um estudo com 18 crianças com suspeita de DC e verificaram que em uma (4\%) a manifestação atípica era constipação.

Nesse contexto, o objetivo deste artigo foi relatar dois casos de pacientes portadores de DC, cuja manifestação clínica atípica foi constipação crônica. O relato foi aprovado pelo Comitê de Ética da Escola Paulista de Medicina da Universidade Federal de São Paulo.

\section{Descrição dos casos}

\section{Caso 1}

Paciente do sexo feminino, com 36 meses de idade, apresentava queixa de constipação desde os 18 meses. Era acompanhada no serviço de Ortopedia do Hospital São Paulo devido à história de torcicolo crônico recidivante (sic). Como apresentava concomitantemente queixa de constipação crônica, foi encaminhada ao serviço de Gastroenterologia Pediátrica da mesma instituição. Segundo a mãe, a partir dos 18 meses a menor passou a ter dificuldade para evacuar, caracterizada por eliminação de fezes endurecidas, de formato cilíndrico, com rachaduras e espessura aumentada. A paciente fazia esforço e sentia dor para evacuar e, em algumas ocasiões, apresentava sangue vivo rutilante em fio de linha recobrindo as fezes. Devido a esses sintomas, fazia uso frequente de lactulose em baixas doses, sem sucesso e, periodicamente, supositório de glicerina.

A paciente recebeu aleitamento natural exclusivo até os seis meses de idade e, durante este período, evacuava duas a três vezes por dia, fezes pastosas, sem dificuldade. A mãe introduziu dieta do desmame a partir dos sete meses, constituída por leite de vaca integral com farinha de cereais (Mucilon ${ }^{\circledR}$ de arroz e aveia) e dieta sólida contendo glúten (macarrão). Como antecedente familiar relevante, a paciente tem uma irmã de seis anos que sofre de epilepsia de difícil controle desde os três anos de idade.
Ao exame físico apresentou peso igual a $11,4 \mathrm{~kg}$ e estatura de $88,5 \mathrm{~cm}$ (ambos os dados antropométricos no terceiro percentil). Apresentava palidez cutânea $+/++++$, massa palpável de consistência endurecida na fossa ilíaca e flanco esquerdo. A inspeção anal não revelou anormalidades e, no toque retal, pode-se palpar pequena quantidade de fezes de consistência endurecida.

Nessa ocasião, foram consideradas as seguintes hipóteses diagnósticas: baixo peso e baixa estatura (escore $Z$ peso/ idade -1,9; estatura/idade -1,6; peso-estatura -1,5), constipação crônica e anemia ferropriva. Foram solicitados os seguintes exames de investigação laboratorial: hemograma, ferro sérico, ferritina sérica, hormônio tireoestimulante, tiroxina livre, urina tipo 1 e cultura, protoparasitológico de fezes e radiografia simples do abdome. $\mathrm{Na}$ ocasião, foi prescrito desimpactação fecal por enema evacuatório com fosfato de sódio mono e dibásico (Fleet enema ${ }^{\circledR}$ ), além de lactulose $\left(\right.$ Lactulona ${ }^{\circledR}$ ) como laxante de manutenção na dose $2 \mathrm{~mL} / \mathrm{kg} / \mathrm{dia}$.

A paciente retornou para consulta após um mês sem relatar alívio da constipação, porém, foi observado que não havia sido cumprido o esquema terapêutico proposto. Em virtude do baixo peso e da baixa estatura, além da identificação de deficiência de ferro e ferritina séricos (Tabela 1), foram solicitados os testes de dosagem do hidrogênio $\left(\mathrm{H}_{2}\right)$ no ar expirado com sobrecarga de glicose (G), lactose (L), frutose (F) e lactulose (Lac) para avaliação da função digestiva-absortiva (Tabela 2), além da determinação do anticorpo antitransglutaminase tecidual (AATG) e imunoglobulina A sérica. Os testes com $\mathrm{G}, \mathrm{L}$ e Lac mostraram valores dentro da normalidade, com elevação dos níveis de $\mathrm{H}_{2}$ no ar expirado $<20 \mathrm{ppm}$ em relação ao nível de jejum. No caso da Lac, espera-se elevação do nível de $\mathrm{H}_{2}$ no ar expirado após 60 minutos, posto tratar-se de carboidrato não absorvível (tal elevação representa a ação fermentativa da flora bacteriana colônica). $\mathrm{O}$ teste com $\mathrm{F}$ indicou má absorção deste carboidrato, porém não revelou intolerância, visto que a paciente não apresentou quaisquer sintomas de intolerância. Em virtude da dosagem do anticorpo antitransglutaminase sérica ter-se revelado acima do valor de referência $(33,62$ unidades - valor de referência menor que 20 unidades), foi solicitada a realização da biópsia de intestino delgado por via endoscópica. A paciente apresentou nível sérico da imunoglobulina A de $111,1 \mathrm{mg} / \mathrm{dL}$ (valor de referência entre 24 a $190 \mathrm{mg} / \mathrm{dL}$ ). A análise histológica evidenciou atrofia vilositária subtotal, com linfocitose intraepitelial difusa e discreto aumento do infiltrado linfoplasmocitário 
na lâmina própria (classificação Marsch 3A) ${ }^{(7)}$ (Figuras 1 e 2). Diante do achado histopatológico foi estabelecido o diagnóstico de DC e introduzida dieta isenta de glúten. Após dois meses do início do tratamento dietético, a paciente passou a apresentar fezes pastosas com frequência diária das evacuações.

\section{Caso 2}

Paciente do sexo feminino, com 30 meses de idade, apresentava queixa de constipação crônica com escape fecal a partir da retirada das fraldas, o que ocorreu aos 27 meses de vida. Segundo a mãe, a paciente apresentava dor para evacuar, com fezes endurecidas e volumosas, sem presença de sangue

Tabela 1 - Investigação laboratorial

\begin{tabular}{lccc}
\hline Parâmetros avaliados & Caso 1 & Caso 2 & Valores de referência \\
\hline Ferro $(\mathrm{mcg} / \mathrm{dL})$ & 32 & 85 & 37 a 170 \\
Ferritina $(\mathrm{ng} / \mathrm{mL})$ & 8,4 & 27,0 & 11,0 a 307,0 \\
Hormônio tireoestimulante $(\mu \mathrm{Ul} / \mathrm{mL})$ & 1,24 & 3,68 & 0,34 a 5,60 \\
Tiroxina livre $(\mathrm{ng} / \mathrm{dL})$ & 0,80 & 1,08 & 0,58 a 1,64 \\
Parasitológico de fezes (três amostras) & Negativo & - & Negativo \\
Urina 1 & Normal & - & \\
Hemoglobina $(\mathrm{g} / \mathrm{dL})$ & 11,5 & 13,5 & 12,0 a 15,5 \\
Hematócrito $(\%)$ & 35,0 & 42,2 & 35,0 a 45,0 \\
\hline
\end{tabular}

Tabela 2 - Teste do hidrogênio no ar expirado - caso 1

\begin{tabular}{lcccc}
\hline & Frutose & Lactose & Lactulose & Glicose \\
\hline Jejum & 0 & 4 & 1 & 0 \\
15 minutos & 0 & 3 & 0 & 0 \\
30 minutos & 10 & 0 & 0 & 0 \\
45 minutos & 27 & 0 & 8 & 0 \\
60 minutos & 36 & 14 & 27 & 1 \\
90 minutos & 15 & 7 & 20 & 1 \\
120 minutos & 10 & 10 & 12 & 0 \\
\hline
\end{tabular}

Teste do hidrogênio no ar expirado com sobrecarga dos seguintes carboidratos: glicose, frutose, lactose e lactulose; valores expressos em partes por milhão (ppm)

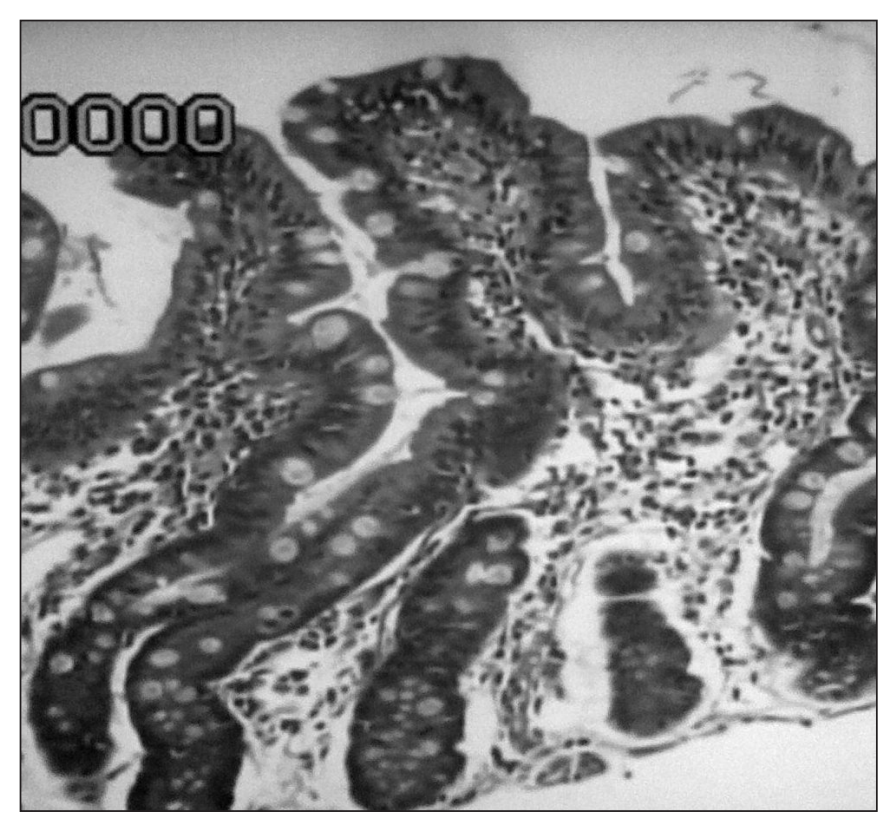

Figura 1 - Biópsia de intestino delgado evidenciando atrofia vilositária subtotal com linfocitose intraepitelial e discreto aumento do infiltrado linfoplasmocitário na lâmina própria (10x HE) - caso 1

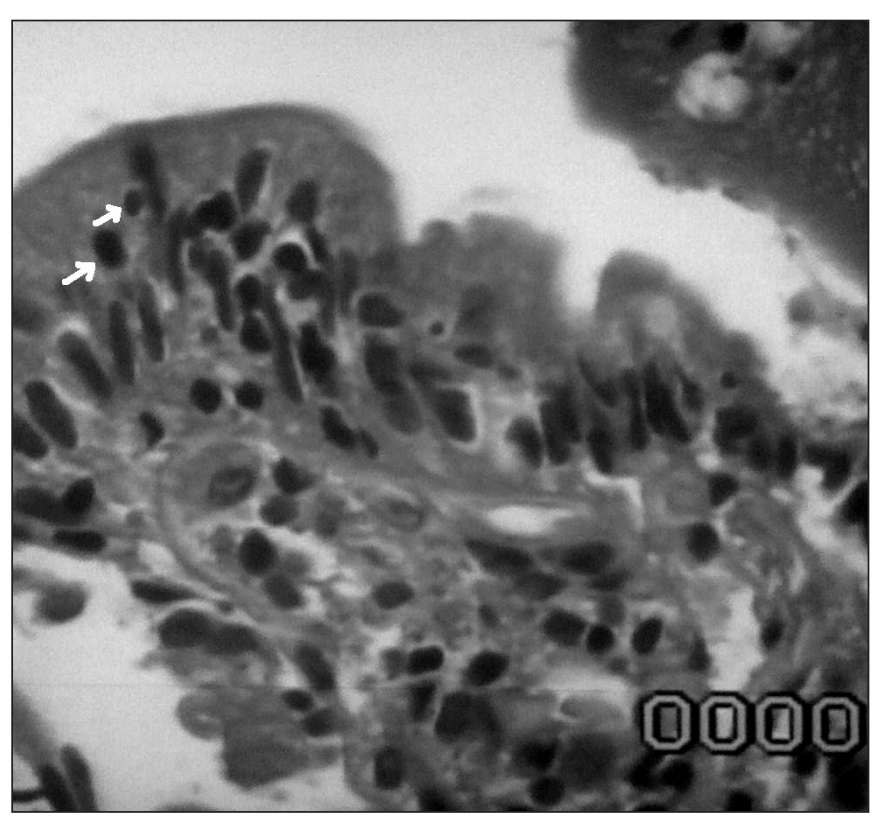

Figura 2 - Biópsia de intestino delgado evidenciando uma vilosidade intestinal com a presença de linfócitos intraepiteliais em grande quantidade, identificados pelas setas (100x HE) - caso 1 
ou outros elementos patológicos, a cada cinco dias. Era medicada com lactulose (Farlac) em dose abaixo da preconizada, sem sucesso. A paciente recebeu aleitamento misto até os oito meses de vida e, durante este período, evacuava duas a três vezes por dia, fezes pastosas, sem dificuldade. A mãe introduziu dieta sólida a partir dos seis meses, constituída por leite de vaca (fórmula adequada para a faixa etária) e dieta sólida própria para a idade, de acordo com a orientação do pediatra. A introdução de farinhas derivadas do trigo se deu nessa ocasião. Como antecedente familiar relevante, o avô é portador de Doença de Crohn (sic) e a mãe sofre de constipação crônica.

Ao exame físico apresentou peso igual a $11,7 \mathrm{~kg}$ e estatura de $92 \mathrm{~cm}$ (escore $Z$ peso/idade -1,37; estatura/idade -0,78; peso-estatura -1,04). Apresentava aspecto emagrecido, abdome distendido com massa palpável no flanco esquerdo. $\mathrm{Na}$ ocasião, foram consideradas as seguintes hipóteses diagnósticas: baixo peso ou constipação crônica. Foi solicitado raio $\mathrm{X}$ simples de abdome, que revelou imagem com excesso de gases e fezes em toda a topografia colônica e sugestão de existência de massa fecal retida na ampola retal. A mãe foi orientada a realizar desimpactação fecal com clister de Fosfoenema e posteriormente manutenção com lactulose ( $2 \mathrm{~mL} / \mathrm{kg} / \mathrm{dia})$ e óleo mineral ( $2 \mathrm{~mL} / \mathrm{kg} / \mathrm{dia})$. Como a paciente manteve a queixa de constipação e retardo do ritmo de crescimento um ano após a conduta inicial, peso igual a $13,1 \mathrm{~kg}$ e estatura de $98 \mathrm{~cm}$ (escore $Z$ peso/idade -1,07), foram solicitados os seguintes exames laboratoriais: hemograma, hormônio tireoestimulante, tiroxina livre e ferritina (Tabela 1). Também foram solicitados os testes sorológicos para rastreamento de DC, a saber: anticorpo antigliadina (AGA) IgA e IgG, anticorpo antiendomíseso (EMA), anticorpo antitransglutaminase tecidual e determinação dos antígenos de HLA DQ2 e DQ8.

Diante dos resultados positivos para os marcadores de DC, a saber: EMA 1/320 (valor de referência - não reagente), AGA IgA 9,9 e IgG 3,6 (valores de referência $\geq 1$ e $\geq 3$, respectivamente), AATG 165, HLA DQ2 +, foi realizada a biópsia de duodeno por via endoscópica. Esta revelou, à macroscopia, imagem da mucosa duodenal em ladrilho, sugestiva da DC. A microscopia óptica comum evidenciou atrofia vilositária de grau moderado, com significativo aumento dos linfócitos intraepiteliais; na lâmina própria havia aumento do infiltrado linfoplasmocitário e hiperplasia das glândulas crípticas $(\text { Marsh } 2)^{(7)}$. A paciente foi orientada a realizar dieta isenta de glúten, com desaparecimento da queixa de constipação um mês depois do início do tratamento dietético.

\section{Discussão}

A DC é uma intolerância permanente ao glúten e é considerada uma enteropatia crônica imunomediada ${ }^{(2)}$. Na Europa e nos Estados Unidos, a prevalência da DC varia de um caso para cada 100 a 200 indivíduos $^{(4)}$. Oliveira $e t$ al ${ }^{(8)}$, em São Paulo, investigando doadores de sangue, demonstraram que a DC não deve ser considerada uma enfermidade rara, sendo sua prevalência de, pelo menos, 1:214 indivíduos.

Além da forma clássica, as outras formas reconhecidas são: 1) Assintomática ou silenciosa - enteropatia típica sensível ao glúten, porém com ausência de manifestações clínicas -, grande parte desse grupo é composto por parentes de primeiro grau de pacientes com DC e pacientes com diabetes dependentes de insulina ${ }^{(4)}$; 2) Não clássica ou atípica - caracterizada por quadro mono ou paucissintomático, com início mais tardio na infância; os pacientes podem apresentar manifestações isoladas como baixa estatura, anemia por deficiência de ferro refratária ao tratamento, artrite ou artralgia, convulsões, hipoplasia do esmalte dentário, dermatite herpetiforme, hipertransaminasemia, puberdade precoce, dor abdominal recorrente e constipação(4). As citações de constipação como um dos sintomas de forma atípica da DC, particularmente em artigos de revisão, são recorrentes, porém, são raras as descrições comprovadas de constipação como sintoma da enfermidade, disponíveis na literatura.

No extenso levantamento bibliográfico realizado, foram encontrados apenas dois artigos que descrevem a constipação como sintoma de DC na faixa pediátrica, os quais foram referidos anteriormente ${ }^{(5,6)}$. Essas raras descrições de constipação como manifestação atípica de DC levaram Hungerford ${ }^{(9)}$, em 1996, a enviar uma carta ao editor da revista Australian Family Physician na qual revelou seu desapontamento pela falta da descrição desse sintoma em crianças, pois, em sua experiência pessoal, constipação crônica não era um sintoma raro em pacientes adultos portadores de DC.

A DC é cada vez mais reconhecida na população adulta sem a queixa de diarreia, com uma porcentagem maior de pacientes que se apresentam como indivíduos assintomáticos, frequentemente detectados em exames de triagem. As formas atípicas estão se tornando mais frequentes ${ }^{(10)}$. A Sociedade Norte Americana de Gastroenterologia Pediátrica Hepatologia e Nutrição recomenda que a DC seja considerada no diagnóstico diferencial das crianças com sintomas persistentes do trato gastrintestinal, incluindo dor abdominal recorrente, constipação e vômitos ${ }^{(11)}$. Em 2007, um estudo multicêntrico realizado nos EUA demonstrou que uma 
intensificação na realização de testes de triagem para DC poderia aumentar a detecção de tais pacientes no país ${ }^{(12)}$. Nesse estudo, realizado entre 2002 e 2004, foram diagnosticados 22 casos de DC em 976 pessoas investigadas e, destas, quatro apresentavam sintomas de constipação. Comparando-se com as taxas de diagnóstico anteriores, observou-se um aumento bastante significativo de novos casos, saltando de 0,27 casos para 11,6 casos em cada mil pacientes investigados.

Nos dois casos descritos no presente estudo, as pacientes apresentavam quadro de constipação crônica, além de valores negativos nas relações do escore $Z$ para peso e estatura. É do conhecimento geral que a prevalência de constipação crônica é bastante elevada na população pediátrica que busca atenção médica em Gastroenterologia e que, em sua imensa maioria, a queixa é decorrente de um transtorno funcional. Entretanto, quando a constipação se manifesta acompanhada

\section{Referências bibliográficas}

1. Sdepanian VL, Morais MB, Fagundes-Neto U. Celiac disease: clinical characteristics and methods used in the diagnosis of patients registered at the Brazilian Celiac Association. J Pediatr (Rio J) 2001;77:131-8.

2. Autoria não referida. National Institutes of Health Consensus Development Conference Statement on Celiac Disease, June 28-30, 2004. Gastroenterology 2005;128 (4 Suppl 1):S1-9.

3. Sdepanian VL, Morais MB, Fagundes-Neto U. Celiac disease: evolution in knowledge since its original centennial description up to the present day. Arq Gastroenterol 1999:36:244-57.

4. Fasano A. Clinical presentation of celiac disease in the pediatric population. Gastroenterology 2005;128:S68-73.

5. Egan-Mitchell B, McNicholl B. Constipation in childhood coeliac disease. Arch Dis Child 1972;47:238-40.

6. Sharma A, Poddar U, Yachha SK. Time to recognize atypical celiac disease in Indian children. Indian J Gastroenterol 2007;26:269-73.

7. Oberhuber G, Granditsch G, Vogelsang H. The histopathology of coeliac disease: time for a standardized report scheme for pathologists. Eur $\mathrm{J}$ de outros sinais de alarme, por exemplo, algum grau de agravo nutricional, este evento deve servir de indicador para que se aprofunde a investigação diagnóstica. Em ambos os casos descritos, durante o seguimento ambulatorial a constipação persistiu associada a um agravo nutricional e, por essa razão, decidiu-se avaliar a função digestiva-absortiva, que resultou positiva para DC.

Em conclusão, é necessário enfatizar que a DC pode se apresentar de múltiplas formas, a saber: sintomática, assintomática e atípica. Apesar de ser escassa a descrição da DC cursando com constipação crônica, esta não parece ser uma manifestação atípica de prevalência desprezível. Dessa forma, é de extrema importância que os profissionais da saúde estejam atentos para esta manifestação considerada atípica, como possível forma de apresentação da DC e, quando tal suspeita for levantada, realizar a investigação pertinente.
Gastroenterol Hepatol 1999;11:1185-94.

8. Oliveira RP, Sdepanian VL, Barreto JA, Cortez AJ, Carvalho FO, Bordin JO et al. High prevalence of celiac disease in Brazilian blood donor volunteers based on screening by $\lg \mathrm{A}$ antitissue transglutaminase antibody. Eur $\mathrm{J}$ Gastroenterology Hepatol 2007;19:43-9.

9. Hungerford C. Constipation can be a sign of coeliac disease. Aust Fam Physician 1996;25:802-3.

10. Rampertab SD, Pooran N, Singh P, Green PH. Trends in clinical presentation of celiac disease in the US over the last fifty years. Gastroenterology 2003; 124 (Suppl 1):A659.

11. Hill ID, Dirks MH, Liptak GS, Colletti RB, Fasano A, Guandalini S et al. Guideline for the diagnosis and treatment of celiac disease in children: recommendations of the North American Society for Pediatric Gastroenterology, Hepatology and Nutrition. J Pediatr Gastroenterol Nutr 2005;40:1-19.

12. Catassi C, Kryszak D, Louis-Jacques O, Duerksen DR, Hill I, Crowe SE et al. Detection of celiac disease in primary care: a multicenter case-finding study in North America. Am J Gastroenterol 2007;102:1454-60. 